\title{
Research on the Construction of Characteristic Towns in China: Models, Problems, Countermeasures
}

\author{
Shaogang Liao, Songdan Yi \\ School of Public Finance and Public Administration, Jiangxi University of Finance and Economics, Nanchang, China \\ Email address: \\ liaoshaogang@163.com (Shaogang Liao) \\ To cite this article: \\ Shaogang Liao, Songdan Yi. Research on the Construction of Characteristic Towns in China: Models, Problems, Countermeasures. \\ International Journal of Sustainable Development Research. Vol. 4, No. 2, 2018, pp. 17-24. doi: 10.11648/j.ijsdr.20180402.11
}

Received: April 27, 2018; Accepted: June 8, 2018; Published: September 5, 2018

\begin{abstract}
In recent years, characteristic towns construction are spreading all over the country. Under the background of New-Normal, the construction of characteristic towns has become a strategic choice for all provinces in the country to coordinate and promote regional innovation and development. It is also an important measure to accelerate the supply-side structural reforms and build new cities. Due to the large differences of the regional economic development in China, the characteristic towns achievements of other provinces cannot be copied completely. High-level characteristic towns should be constructed according to different local conditions. Taking the construction of characteristic towns in Jiangxi Province as an example, this paper analyzes the current construction status, models, and problems of the characteristic towns in China. Finally combining the achievement of the well-known characteristic towns construction at home and abroad, the author proposes several construction countermeasures.
\end{abstract}

Keywords: Characteristic Towns, Construction Status, Developing Models, Countermeasures

\section{Introduction}

The construction of characteristic towns is not only an important step for cultivating emerging industries and promoting industrial transformation, but also a reform measure to optimize the urban and rural system and create innovation carriers. The earliest domestic concept of the Characteristic town originated in Zhejiang Province. "Characteristic Town" was first mention by Li Qiang, the governor of Zhejiang Province, at the Alibaba Cloud Developer Conference held in Yunqi Township. Then it became one of the key words in the report of "Government Work" passed by the Third Session of the Twelfth National People's Congress of Zhejiang in January 2015. The "Guiding Opinions on Accelerating the Planning and Construction of Characteristic Towns" announced by provincial government clearly defined the positioning and requirements of the Characteristic towns until April 22. Characteristic town refers to a development space platform that is relatively independent from the urban area and has a clear industrial orientation, cultural connotation, tourism and certain community functions. It is distinguished from administrative division units and industrial parks. Its main features include: distinctive features, green ecology, industrial development, beautiful and livable. Usually Characteristic town can be a composite carrier of industry, culture, tourism, and community integration. [1] The "Guidance Opinions" clarified that the planning area of characteristic towns is generally controlled at about 3 square kilometers, and the construction area is generally controlled at about 1 square kilometer. In principle, the fixed assets should be invested 5 billion yuan in three years, and all characteristic towns will be built into scenic spots at least $3 \mathrm{~A}$ grade.

\section{The Current Construction of Characteristic Towns in China}

China is vast in territory. Very great difference exists in such aspects as resource natural endowment, economic base, engineering level in each area. Which makes the functional definition and development model of characteristic towns in different provinces, cities, and regions different. But different models have their own advantages such as in Figure 1. The eastern areas, such as Zhejiang and Jiangsu province, have a relatively high level of economic development and complete industrial structure. At the same time, they have very 
significant geographical advantages. The central areas, such as Jiangxi and Anhui province, whose ecological forests are densely populated with pure air, and the tourism industry has great potential. While the western region has a low level of economic and social development, it has a unique cultural atmosphere and industrial characteristics, such as Yunnan, Guizhou, Sichuan province and other places. How to use the advantages of each region to build characteristic towns is essental. [2] According to the actual situation of the development of small towns with Chinese characteristics, the development model of small towns with distinctive features is divided into four categories: Location-based, Industry-based, Cultural-induced, and Government-led.

\section{(1) Location-Based}

Environmental advantages, convenient transportation, and perfect public infrastructure are characteristics of livability that small cities and towns generally have. The location of towns is also important, mainly reflected in the functional orientation of the town and the choice of industry types. Xiaoshan Kongxiang Town located in Hangzhou Airport Economic Zone, connecting the Xiaoshan International Airport and the downtown area of Hangzhou with obvious location advantages. The local government took advantage of this geographical position to vigorously develop smart logistics and has established a global collaborative, green and smart airport town.

(2) Industry-Based

Industrial characteristics are the core embodiment of a characteristic town. Abandoning the "big and full", pursuing "small and refined" is the basic requirement of the town's industry positioning. Characteristic towns have a clear leading industry. They are generally based on technology-intensive emerging industries or tertiary industries with higher value-added products, and other industries are all relateo the theme industry. For example, the development of Tsingtao Brew Garden Town is to use the existing brand value of "Tsingtao Brewery", which greatly shortens the cultivation time of the town and converts the brand value into actual profit. The fund town of Hangzhou, taking advantage of the high concentration of Hangzhou's wealth capital, develops financial services as the theme of financial innovation, and provides taxation services and various types of administrative services to surrounding businesses in the town. With the leading position of Alibaba's e-commerce industry, Hangzhou Yunqi Town has attracted many high-quality enterprises in e-commerce industry gathering here, forming the development of e-commerce industry, cloud industry and other characteristic industries.

\section{(3) Cultural-Induced}

Regional culture is another manifestation of characteristic town "feature". It can become a town's name card more than industry, and it is a new growth point for Chinese small towns' economy. Regional culture includes tangible resource elements such as local characteristic buildings, cultural celebrities and traditional crafts, as well as invisible informal systems such as customs, cultural traditions, and so on. All of these can become the main resources for the birth of culture, which in turn drives the development of tourism, specialty industries, and thematic activities. For example, Hongcun Village in Anhui Province, which is called "the village of painting". Until 2014, the town still preserved more than 140 houses in the Ming and Qing Dynasties, forming a cultural tourism ancient town represented by Huizhou architecture.

(4) Government-Led

This type town mainly relys on the government's active promotion. The government, through the formulation of the township strategy, supports small cities and towns that have a certain industrial base. It will focus on strengthening the industry base of characteristic towns and promoting the construction and development of characteristics towns. The characteristic towns such as Boao Town and Xiaoshan Robot Town are both characteristic towns that rely on government policies to promote the production. For example, since the government selected Boao as the permanent place of forum for Asia, the town has enjoyed preferential policies ranging from infrastructure construction to industrial development support. The annual Boao Forum for Asia is held here, which injects new vitality to local industry, especially in the development of exhibition industry.

The construction of characteristic towns in China is relatively later than other country. Most of small towns do not have the advantage of market competition in their characteristic industries, and their social infrastructure and services are also insufficient. At present, the government supporting policy is the most important opportunity for the construction and development of characteristic towns. In most towns, the initial development model is government-led. However, with the continuous development of the construction of small towns with unique characteristics, technological innovation has become the core concern of characteristic towns. Through technical innovation, the market competitiveness of characteristic industries will be improved, the industry will lead the development of small towns. The characteristic town development model will also gradually evolve from Government-led type transformed into Industry-oriented type.

Table 1. Four Models of Characteristic Towns in China.

\begin{tabular}{ll}
\hline Models & Feature of Towns \\
\hline \multirow{2}{*}{$\begin{array}{l}\text { 1. The small town has a superior geographical location, and the regional resource advantages determine the } \\
\text { town's characteristic industries; }\end{array}$} \\
$\begin{array}{l}\text { 2. Government supporting policies play a important role in the development of small towns and encourage the } \\
\text { innovation and development of the main industries. } \\
\text { 1. The leading enterprise is the core of the town, and the development of the enterprise is integrated with the } \\
\text { Industry-based } \\
\text { construction of the town; } \\
\text { 2. Industrial clustering has brought opportunities for industrial restructuring and upgrading of small towns and }\end{array}$ \\
\hline
\end{tabular}




\begin{tabular}{ll}
\hline Models & Feature of Towns \\
\hline & $\begin{array}{l}\text { improved regional competitiveness. } \\
\text { 1. The town has a rich historical and cultural heritage, unique cultural resources determine the town's } \\
\text { characteristics of the industry; } \\
\text { 2. Organizations, colleges, research institutes, social mediation and other organizations have instilled vitality } \\
\text { into the construction of characteristic industries. } \\
\text { 1. Natural conditions are the basic conditions for the construction and development of such characteristic towns; } \\
\text { 2. The government plays a central role in the construction of such towns, formulating corresponding supporting } \\
\text { policies, strengthening infrastructure construction, providing talents, funds, and technical support; } \\
\text { 3. The government provides support for the innovation and development of town-specific industries. }\end{array}$ \\
\hline
\end{tabular}

Data source: Public information

\section{The Basic Development Models of Characteristic Towns in China}

According to the actual situation of the characteristic towns development in China, the development models of characteristic towns in China are mainly divided into five categories: natural resource orientation, government-led, large-enterprise-led, production-study-research orientation and social intermediary organizations ${ }^{1}$. First, natural resource oriented type. [3] This type mainly relys on the rich natural resources of the region and give full play to the advantages of natural resources, and gradually form distinctive local characteristic industries. Such as Yuecheng Yellow Wine Town and Longquan Celadon Town located in the plains of the middle and lower reaches of the Yangtze River. The second is government-led type. This type mainly relys on the government's policy support and rely on government forces to promote the development of characteristic towns. For example, the well-known Boao small town in Qionghai and Xiaoshan robotic town are both this category. They have preferential policies from all levels of government from infrastructure construction to industrial development support. Virtually the government plays an important role in protecting the development of these small towns. The third is large-enterprise-led. As the main part of market economic activities, enterprises play an important role in industrial development and regional development. Especially leading enterprises have played a positive role in the development of the industry. Once enterprises gather in a certain area and form industrial clusters, they can bring opportunities for the development of local industries. Hangzhou Yunqi Small Town is the place where Alibaba Group is located. The town has attracted many high-quality companies of the e-commerce industry, forming an e-commerce industry cluster and stimulating the economic and industrial development of small towns and surrounding areas. The fourth is production-study-research orientation. It refers to the efficient combination between enterprises, universities, and scientific research institutions giving play to their respective advantages, and thus forming a characteristic industry. For example, Lin'an Cloud Manufacturing Town mainly relies on Qingshan Lake Science and Technology City, neighboring scientific research

1 Wei Jiao. Characteristic Towns Development Models and Efficiency Improvement Methods in China institutes and entrepreneurial companies that cultivated a group of talents with innovative awareness and practical ability. This has attracted a group of companies that are engaged in cloud manufacturing technology research and development and engineering technology services, which promoted the rapid development of functional manufacturing. Fifth, social intermediary organizations play an important role in the formation and development of characteristic towns. In particular, under the conditions of large scale of business associations, industry associations, and strong market influence, social intermediary organizations can promote the development of regional characteristic industries and accelerate the construction of the small town. Liushi Town is known as the "Capital of China's Electrical Appliances" where the most famous Chinese enterprises have entered the " Chinese Enterprises Top 500 ", including Zhengtai Group and Delixi Group. All in all, China has a vast territory that led to a big difference in developing characteristic towns in different regions. However, the development models of characteristic towns in our country is dominated by government-led and large - enterprise - led, and natural resource orientation, production-study-research orientation, and social intermediary organizations are a small number. [4]

\section{The Main Construction Problems of Characteristic Towns in China-A Case Study on Jiangxi Province}

At present, the Ministry of Housing and Urban-Rural Development has published 403 towns as national characteristic towns. Judging from the distribution of these towns, Zhejiang ranked first with 23 characteristic towns, and Jiangsu, Shandong provinces ranked in second place respectively. However, Jiangxi ranked 17th in the country. It can be seen that the number of characteristic towns in Jiangxi Province is relatively less than others. The reason for this is that the characteristic towns development in Jiangxi Province start late and lack of sufficient experience. It should be known that there are still many problems in the construction of characteristic towns in Jiangxi Province. And these problems also exist in other provinces and cities. [5] There are several common problems in the construction of characteristic towns: unclear industrial features, lack of professional planning for townships; lack of supporting policies; lack of professional talents and financial support; unclear market main body; 
facilities infrastructure and public service capacity can not keep pace with the development of towns.

(1) Unclear Industrial Features, Lack of Professional Planning for Townships

"Feature" is the core element of characteristic towns. A small town must have a unique industry that differs from others. However, some characteristic towns' industries are inconspicuous and its development orientation is unclear, and there are many similarities development orientation in China. From the above analysis, it can be known that 10 of the 12 state-level characteristic towns in Jiangxi Province are mainly based on tourism development, and various towns have the problems with industrial characteristic overlapping. As shown in Figure 2:

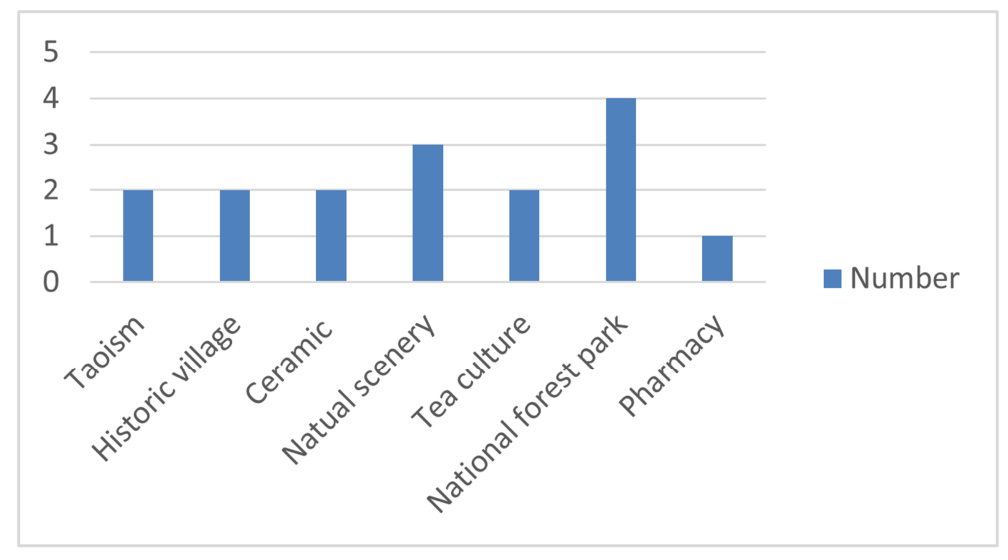

Data source: Public data

Figure 1. The Cross-overlapping of Different Towns Industry.

From the Figure 2, It can be find out that the cross-overlapping of characteristic towns in Jiangxi Province is serious. It shows that the national forest parks of four characteristic towns are taken as featured scenic spots, and three characteristic towns create tourist towns based on the theme of ornamental natural scenery. These cross-overlapping industries led to ambiguous industrial features between different towns. So that they deviated from the core of construction and caused characteristic towns losing their "feature". From the side of town planning, the design of characteristic small towns should be planned according to the actual conditions of regional development and their own core competitiveness. The combination of "production, city, person, and culture" is the fundamental principle. It can learn from the developed countries in construction of characteristic towns, such as the United States and European countries. They all have one thing in common: they focus on prompting the development of small towns with feature industry. Although the economic development speed of Jiangxi Province is relatively slow compared with the cities in eastern China, it has significant geographic advantages and abundant ecological, agricultural and cultural resources. Each region should grasp the three elements of economy, ecology, and culture to plan and design and accurately position the development direction of characteristic towns.

(2) Lack of Supporting Policies

At present, the support policies of characteristic towns can be divided into land planning policy, fiscal policy, financial policy, talent policy, government authority and reform supporting policies. Comprehensive analysis of the supporting policies for characteristic towns, the land planning policies, the fiscal, taxation financial policies are almost all mentioned. But the relevant supporting policies on how to nurture characteristic towns and keep them growing are rarely mentioned. Obviously, the current policy is mainly about the land and financial guarantees. The relative lack of policies to stimulate the development vibrancy of characteristic towns. Paying much attention to the external development guarantees and lacking of internal motivation, the policy system needs to be adjusted. ${ }^{2}$

Zhejiang People's Government promulgated the "Guiding Opinions on Accelerating the Planning and Construction of Characteristic Towns" in April 2015, clarifying the general requirements, creation procedures, policy measures, organization and leadership of characteristic town planning and construction. In the same year, relevant documents were promulgated to accelerate the construction of Characteristic Towns such as the "Notice on Promoting the Construction of Characteristic Towns with E-Commerce" and the "Guidelines for the Creation of Characteristic Towns in Zhejiang Province". In 2016, the General Office of People's Government of Zhejiang Province Promulgated the "Notice on Accelerating the Construction of Characteristic Towns with High Quality". In September 2016, Shandong Province promulgated the "Implementation Plan for the Creation of Characteristic Towns in Shandong Province". Since the approval of the first batch of state-level characteristic towns, People's Government of Jiangxi Province has only published the "Notice on Construction Project for Characteristic Towns in Jiangxi Province" at 20th December, 2016. The government plans to establish 60 characteristic towns by two batches before 2020. Other supporting policies related to the construction of characteristic towns are not formulated. The

\footnotetext{
2 Zhiyong Lai, Xiang Luo. Analysis of the Planning and Construction Policy System of Chinese Characteristic Town
} 
government's supporting policy of Jiangxi province on characteristic towns is still insufficient, compared with other provinces and cities. The government should give the town the appropriate financial incentives and land policies to settle the troubles of the township construction and ensure the development of the town.

(3) Lack of Professional Talents and Financial Support

Lacking talents has become a key factor that restricts the development of characteristic towns. From the analysis of characteristic towns development, the talent can be mainly divided into two types: management talents and professional talents. The existing grass-roots cadres are still the original township cadres with a small staffing. Their management philosophy still remains at the traditional township management level, and they lack experience in building characteristic towns. The second is the lack of professional talents in characteristic towns' construction. Although it is possible to learn from other provinces, establishing research institutes and incubation parks and attract talents by attractive treatment. However, the young professionals in nowadays often have higher demands with working environment. Moreover, ordinary towns are not attractive enough for talent elites and professional teams. In addition, the construction of characteristic towns can not be developed without large amounts funds and characteristic industries. Since these towns do not have administrative authority, they can not get financial supporting from the higher level government. So they have to find other ways to attract investment and absorb social capital. At present, most towns have common problems such as poor infrastructure, high development costs, and long investment cycles so that many investors are unwilling to invest. In addition, the government has not promulgated preferential policies on fiscal policy timely, resulting in the financial industry didn't play a corresponding role. And banks have not provided special purpose loans for characteristic towns or preferential interest policies.

\section{(4) Unclear Market Main Body}

The operating mode of characteristic towns is guided by government and operated by market when enterprises as the main body. Among them, the government plays a guiding role in providing service guarantees for the construction of towns. The market plays a decisive role in the allocation of resources and enterprises is at the dominant position. The construction of characteristic towns should take full advantage of the "invisible hand of the market". But at present, some local governments have interfered too much with the construction of characteristic towns. They have not cooperated well with the invisible hand of the market, and market was hard to play its role, which has hindered the development of the town. The development of the main body of market operations. The government should not monopolize the power and they should delegate power to market and follow the operating model of towns. On the other hand, this new economic form of characteristic towns is proposed and guided by the government. However, building a characteristic town can only be an empty talk if only the government is warm to build while the enterprises are indifferent and uninterested. Therefore, it is a severe challenge for the government to deal well the relationship between the government and the enterprise in fully tapping the market forces and playing a leading role.

(5) Facilities Infrastructure and Public Service Capacity Cannot Keep Pace with the Development of Towns

At present, most villages and towns in Jiangxi Province have the problem of poor tourism infrastructure and imperfect public service facilities in the process of developing rural tourism. Characteristic towns are not a task project. Some local towns "face" is good-looking, but the infrastructure and public services "inner" in the scenic spot are insufficient. Attractions roads, parking lots, toilets, garbage and sewage treatment, water supply and power supply facilities are inadequate. These soft powers of characteristic towns are not properly valued. When the development of small cities and towns in our country welcomes a new opportunity, the government should fill in the shortcomings of the infrastructure and public services in the planning and construction of characteristic towns, provides good production and living services for the surrounding villages, and then promotes and nurtures the construction of the town according to local conditions. [6]

\section{The Countermeasures for Construction of Characteristic Towns}

(1) Accelerate Scientific Planning and Clarify Industrial Positioning

The characteristic town industrial chain has a strong theme reflecting "small and refined". Identifying the industrial orientation of a town plays a crucial role in building a characteristic town. Firstly, a clear theory system must be constructed in characteristic towns building. In practice, local town development plans and assessment indicators should be established according to the actual conditions of each region. In addition, The construction of towns must do well in scientific planning. In view of the fact that the country has not yet formulated a guideline for the development of characteristic towns, the provincial party committee and provincial government should promptly issue guiding opinions and give clear positioning to develop towns and defuse the current difficulties encountered in the construction of the town. It will become the key factor to decided whether characteristic towns can be an engine of economic development by how to reasonable layout the towns and set up different industrial characteristic and different scales towns. From the review of well-known towns at home and abroad, such as "Dream Town" in Zhejiang Province, "Hangzhou Yuhuangshan South Fund Town", and "Yunqi Town". They all seized the advantages of their industries and achieved value reengineering by new operating mechanism. Hershey, a candy-making town with more than 100 years of history, starts as a chocolate factory and then becomes a prestigious chocolate-themed tourist town in the United States. In the center of the town are three modern chocolate factories, completed with community functions such as department 
stores, Hershey banks, Hershey restaurants, clubs, churches and schools. The tourism function of the town is also quite complete. There are modern amusement facilities such as demonstration workshops, Chocolate World Museum and Hershey Park. Its functional composition is comprehensive and is no longer a single traditional production function. [7]

For better development, characteristic towns must have its own brand and innovate the brand, and emphasize the brand's systematic development. In addition, they should learn excellent construction experience from domestic and foreign characteristic towns, but refuse to apply imitation simply. For example, characteristic towns of Jiangxi province can combine the advantages of Jiangxi, relying on Jiangxi's unique environment, history, and humanities conditions to develop a development path that is in line with Jiangxi's characteristic and has guiding significance for the country.

(2) Perfecting Related Supporting Policies

The cultivation of characteristic towns cannot develop without government's support. Perfecting supporting policies plays the role of escort in nurturing characteristic towns. Zhejiang Province has issued guidelines for accelerating the planning and construction of characteristic towns and set up a joint working conference system in which the executive deputy governor serves as the convener ${ }^{3}$. It also pointed out that it will cultivate characteristic towns about 100 . However, the development of characteristic towns in Jiangxi province starts relatively late, and the systems and evaluation systems in various aspects are still lagging behind. In addition, the focus of characteristic towns is "feature", and the construction of characteristic towns should take the path of innovation and development. It is necessary to improve the original system and methods in innovation. Characteristic towns also should clear in all aspects of specific qualification indicators, determine the assessment system, including land resources, water resources systems, clean energy, green buildings, green transport, ecological environment, solid waste utilization and low-carbon industries. [8] The township construction of Jiangxi Province can set up a special working group for the construction of characteristic towns. At the same time, it can be supplemented with the support of corresponding financial elements, constantly promoting the upgrading of towns, paying attention to actual results, and gradually forming a policy system with Jiangxi feature. On the other hand, other cities in Jiangxi Province can also issue planning documents and creation plans for characteristic towns based on their own regional advantages and make the government give more policies support and guidelines.

(3) Introducing Professional Talents and Try PPP Financing Mode Actively

In current situation, attracting professional talents by great rewards is not a good way that can last for a long time when characteristic town is small scale and not well-known. Colleges have relatively complete disciplines and professional talents. Especially multidisciplinary comprehensive research

3 Xinping Ge, Guangquan LI. <Promoting the Development of Characteristic Towns by Innovation>, universities which is better and more professional, compared with the folk think-tank. The concentration of human resources and the complete range of disciplines in universities are conducive to solving the comprehensive problems about different disciplines, such as natural sciences, engineering technology, humanities and social sciences. The government can build long-term cooperation between townships and universities to come into being a "think-tank" for the development of characteristic towns. This will provide important support for the development of small town in policy making. In addition, it can also formulate special preferential policies to attract technology and professionals from other places to return home. Attracted by preferential policies and homesickness, people with lofty ideals must be more willing to stay in their hometowns.

At present, the building funds for characteristic towns is mainly come from enterprises and the government's preferences policies. However, this does not provide sustainable and stable funding for the construction of characteristic towns. Therefore, the government can actively try the PPP model. As a very effective financing model, PPP can solve the problems of insufficient funds and unsustainable funds in the construction and development of characteristic towns. In addition, it is also possible to encourage the development main body to form investment companies by holding shares, in order to attract private capital to participate in the construction of towns. [9] Not only can it relieve government financial pressure, but it can also use limited financial resources to leverage social capital, make up funding gaps, and broaden sources of funding. However, in the early decision-making and planning of PPP, if the top-level design and planning capacity is weak and social capital selection is improper, which will inevitably bring difficulties to the development of the town. Therefore, the government should learn some successful experience from other province or other country and make good arrangements and plans, which will help promote the smooth operation of the cooperation mechanism between the two sides. Summarizing based on this can provide case support for the construction of other towns.

For example, Yonghe Town in Ji'an County of Jiangxi Province utilizes an innovative investment development model. With the principle of government guidance, business entities, and market operations, it takes the "government + industry + fund" development path and introduces companies to invest in the construction of a pottery town. The company will raise 3 billion yuan in 5 years to build Jizhou Kiln pottery arts town. At that time, they will focus on the Jizhou Kiln and ceramic culture to promote talents, capital, projects, markets and other elements to the small towns. With integrative development of economy, culture, tourism and ecology, the ceramic art industrial agglomeration area can be created by promoting industrial clustering, industrial innovation and industrial upgrading of the pottery town. [10]

(4) Defining the Main Body of Market Operations, Building an Operating Team

According to the design of the "Guiding Opinions", characteristic towns construction should adhere to 
government guidance, enterprise body, and market operation, which highlights the dominant position of enterprises, gives full play to the decisive role of the market in resource allocation, and strengthens government guidance and service guarantees. It will play a better role in planning and preparation, infrastructure support, resource factor protection, inheritance of cultural connotation, and environmental protection. In general, the government plays an extremely important guiding role in the early stages of the construction of characteristic towns. However, although some towns are nominally market-oriented themes, the actual management of operations is subject to the government. In addition, the construction of characteristic towns is based on villages, townships, and towns, and it is difficult to develop relying on their own. Local governments should build relevant platforms, provide innovative services, guide and mobilize the enthusiasm of enterprises, and use various means and forms to create opportunities for the development of enterprises. In accordance with the principle of separation of government and enterprises, a scientific decision-making mechanism can be established and investment entities that are in line with the development orientation of the town can be selected. The investment company can unify the management and undertake various tasks for the development and construction of the town. The government should shift its focus to creating an environment of fair competition for enterprises, strengthen market supervision, and highlight the nature of services in the construction of towns, rather than just issuing orders.

In addition, establishing a professional operating team for each town, equipped with leading figures, matching planning and construction, industry investment, travel planning and other personnel, which can be good for construction and future operations management of the town. Taking Yonghe Town of Jiangxi Province as an example, in order to promote the cultivation and creation of Yonghe characteristic towns, their government established the promoting leading group of Jizhou Kiln Pottery Town, strongly promoted the construction of the Jizhou Kiln Pottery Town.

(5) Strengthening Infrastructure Construction and Improving Public Service Quality

With the improvement of infrastructure such as high-speed railways, highways and airports, and the rapid spread of mobile phones, computers and the Internet, the space-time distance between small towns and the outside world has been greatly shortened, bringing new opportunities to small towns. However, in the early days of the township construction, most of characteristic towns are far away from the municipal centers, and their infrastructure and public services are relatively backward. To quickly develop and became a well-known characteristic town, infrastructure construction and public service capabilities must first be improved. Local governments can set up pre-assessment mechanisms to pre-assess the infrastructure and public service capabilities of characteristic towns, and then the towns with poor infrastructure and public service capabilities are one of the core tasks of the construction. In addition, infrastructure construction generally adopts the method that mainly relys on local governments and supplemented by state subsidies. As a result, the pressure on local finances is huge and the government does not have enough funds to invest in infrastructure and public services. At this point, the government can obtain capital support through the financing of infrastructure construction.

On November 21, 2016, the government of Guangzhou City issued the "Guidelines for the Construction of Standards for the Deployment of Basic and Public Service Facilities in Characteristic Towns of Guangzhou City", which attracted bidders to provide basic and public service facilities for characteristic towns in Guangzhou by means of open tendering. [11] The local governments in Jiangxi Province can also plan and issue corresponding policies in advance, so as to attract powerful suppliers to bid. This will not only reduce the government's financial burden, but also attract private capital and spread risks. The above-mentioned townships can choose suitable strategies according to their situation. Only when the government realizes the importance of infrastructure and public services to the development of characteristic towns, can it be better to take corresponding measures to supplement infrastructure and public services. So that characteristic towns can really get a comprehensive and healthy development.

\section{Conclusion}

At present, the total economic volume of the cultural industry in China continues to grow rapidly, and the good development of the cultural industry provides a favorable environment and referential experience for the development of the cultural tourism industry in characteristic towns. However, nurturing characteristic towns is a long-term task and has its own inherent regularity. The economic development of Jiangxi province is slow, but ecological, agricultural and cultural resources are abundant. So characteristic towns construction can focus on its own advantages. Different provinces and cities can also stimulate the integration of the cultural and creative industries through various forms of development such as "culture+ tourism," "culture+ ecology," "culture+ characteristic agriculture," and "culture+ internet" and strive to create their own characteristic cultural brands, promote the sustainable development of characteristic towns, eventually promote the transformation of new urbanization and economic structure. [12] At the same time, innovation and exploration should be injected into the construction of characteristic towns, and the government should embark on a unique construction road that meets our own characteristic towns development as early as possible.

\section{References}

[1] Yinyin Zhu. Research on the Characteristic Town Construction Current Status and Countermeasures of Zhejiang Province---A Case Study on Jiaxing City [J]. Journal of Jiaxing University, 2016, 28 (2):49-56. 
[2] Mingyi Chen, Yongzi Liu. Research on the Characteristic Town Construction Current Status and Countermeasures of Guangdong Province [J]. Guangdong Science and Technology, 2017, 26 (3):75-79.

[3] Weiwen Zhang. Creating Characteristic Towns: Governments' Positioning and Complement [J]. Journal of Zhejiang Social Sience, 2016 (3):43-45.

[4] Xiaoqing, Ruoyun Li, Cenyu Wang. Problems and Suggestions on Financing of Characteristic Town Infrastructure Construction [J]. Cooperation Economy and Technology, 2017 (15):82-83.

[5] Notice of the Ministry of Housing, and Urban-Rural Development, the National Development and Reform Commission and the Ministry of Finance on Developing the Cultivation of Characteristic Towns (2016) No. 147 [J]. Architectural Design Management, 2016 (9):29-30.

[6] Junjie Li, The Construction of Characteristic Towns Must Complete the Shortcomings of Infrastructure and Public Services [N]. 2017 (5).
[7] Tie Li, The Reflection under the Hot Tide of Characteristic Town [J]. Zhongzhou Construction, 2017 (6):48-50.

[8] Yinyin Zhang, Yuan Ding. The References of Foreign Characteristic Towns for the Construction of Characteristic Towns in Zhejiang Province [J]. Small Town Construction, $2016(11)$

[9] Wei Jiao. Characteristic Towns Development Models and Efficiency Improvement Methods in China [J]. Research on New Urbanization. 2018. 02-0094-06.

[10] Zhiyong Lai, Xiang Luo. Analysis of the Planning and Construction Policy System of Chinese Characteristic Town [J]. Beijing Planning and Construction, 2017 (3):119-121.

[11] Longbao Wei, Xinjie Shi. Considerations and Suggestions on the Construction of Characteristic Towns in Zhejiang Province [J]. Journal of Zhejiang Social Sience 2016 (3).

[12] Yi Huang, Jianqi Tan. The overview of Researches Methods and Construction Principles on Characteristic Towns [J]. Journal of Guangxi Economic\& Management Cadre College, 2017, 29 (1):93-98. 